\title{
Educação repressiva e educação emancipadora: notas acerca da personalidade autoritária e seus desdobramentos na educação
}

\author{
Anita Schlesener \\ https://orcid.org/0000-0002-5185-2604 \\ ${ }^{1}$ Universidade Tuiuti do Paraná, Programa de Pós-graduação em Educação, Curitiba, PR, Brasil
}

Educação repressiva e educação emancipadora: notas acerca da personalidade autoritária e seus desdobramentos na educação

Resumo: O objeto deste estudo é a educação repressiva como instituinte da estrutura social e como refletir, nestas condições sociais, sobre uma educação emancipadora. O conceito de educação que pressupomos aqui é o de que o nosso processo de socialização forma a nossa percepção e a nossa concepção de mundo, numa dinâmica que se estende do nascimento até a morte. Educar implica preparar para um projeto de civilização, o que revela o conteúdo político do processo educativo. Para desenvolver este estudo retomamos a pesquisa interdisciplinar do Grupo de sociólogos e psicólogos publicado em 1950 sobre a personalidade autoritária, a fim de explicitar o fenômeno do preconceito e seus traços na formação da personalidade, não apenas da perspectiva sociopsicológica, mas também política e educacional. Salienta-se a atualidade do tema ante a ascensão de movimentos conservadores e reacionários neste início de século.

Palavras-chave: Autoritarismo. Educação Repressiva. Educação Emancipadora.

Repressive education and emancipatory education: notes about authoritarian personality and its consequences in education

Abstract: The object of this study is repressive education as an institution of the social structure and how to reflect, in these social conditions, on an emancipatory education. The concept of education that we assume here is that our socialization process forms our perception and our conception of the world, in a dynamic that extends from birth to death. Educating implies preparing for a civilization project, which reveals the political content of the educational process. To develop this study, we return to the interdisciplinary research of the Group of sociologists and psychologists published in 1950 on the authoritarian personality, in order to explain the phenomenon of prejudice and its traits in the personality formation, not only from a socio-psychological perspective, but also from a political and educational perspective. It should be noted the relevance of the topic before the rise of conservative and reactionary movements at the beginning of this century.

Keywords: Authoritarianism. Repressive Education. Emancipatory Education.

Recebido em 13.10.2020. Aprovado em 15.12.2020. Revisado em 17.02.2021.

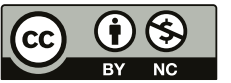

Este é um artigo publicado em acesso aberto (Open Access) sob a licença Creative Commons Attribution NonCommercial, que permite uso, distribuição e reprodução em qualquer meio, sem restrições desde que sem fins comerciais e que o trabalho original seja corretamente citado. 


\section{Introdução}

É destino que a morte da burguesia coincida também com o desaparecimento de todos os valores de moralidade e de coragem. Nesse sentido, os fascistas são bons agentes funerários (GRAMSCI, 1978, p. 191).

Partimos do pressuposto que todo o processo de formação da sociedade, processo que entendemos como educação em sentido amplo, tem como base de sustentação as mais variadas formas de controle e repressão. O conceito de educação que pressupomos aqui é o de que o nosso processo de socialização forma a nossa percepção e a nossa concepção de mundo, numa dinâmica que se estende do nascimento até a morte. Educar implica preparar para um projeto de civilização, o que revela o conteúdo político do processo educativo. $\mathrm{Na}$ sociedade capitalista, a educação se apresenta como um processo de adaptação dos indivíduos às necessidades e exigências do modo de produção, processo educativo que ocorre a partir das relações familiares e sociais e, mais especificamente no sistema escolar.

Nosso esforço tem sido em explicitar, por meio da psicanálise de Freud e do marxismo (na vertente marxiana e da teoria crítica), a noção de educação repressiva, a fim de identificá-la na prática cotidiana e no senso comum para, em decorrência, esclarecer os caminhos para uma educação emancipadora. Tais caminhos implicam fazer a crítica do conhecimento reificado e transmitido de forma dogmática, a crítica ao senso comum e ao modo de apropriação da tradição. Uma educação emancipadora supõe a tentativa de criar, no bojo da sociedade capitalista, um novo projeto social alternativo.

$\mathrm{O}$ argumento inicial que pretendemos desenvolver baseia-se em um escrito de Horkheimer (Prefácio) a propósito da pesquisa interdisciplinar de Theodor W. Adorno, Else Frenkel-Brunswik, Daniel J. Levinson e Robert Nevitt Sanford sobre a personalidade autoritária. O "tema central da obra consiste em supor - e em procurar demonstrar - que o antissemitismo faz parte e é expressão de uma ideologia mais complexa", a qual se caracteriza pelo conservadorismo político (JERVIS, 1997, XXIII). A formação do caráter autoritário se faz preferencialmente na família, num processo educativo que se completa com a religião.

Este tema apresenta uma grande atualidade se pensarmos nos meios de comunicação de massa e no modo como as redes sociais ativam as forças emocionais para direcionar a vontade dos indivíduos para seus objetivos e interesses econômicos. Ações políticas são motivadas pelo ódio racial e conflitos eclodem na medida em que as emoções se acirram, colocando em risco o já frágil contexto da democracia. A acirrada disputa pelo poder, os slogans utilizados em campanha política, a manipulação das ideias por meio das redes sociais nos faz "tomar consciência, de modo intelectual, visceral, existencial e experiencial do impacto da Guerra Híbrida" (GONÇALVES, 2020, p. 7)1.

Com a implementação do neoliberalismo e o avanço do conservadorismo em escala mundial, ressentimentos e preconceitos que supúnhamos superados, ressurgem como fantasmas de um passado a assombrar o presente e a ameaçar as conquistas civilizatórias. Como realçam Stefanuto e Bueno (2020, p. 35), o neoliberalismo veio para exigir "novos sacrifícios dos indivíduos" e para reeditar "velhos sacrifícios", com "novas artimanhas que indicam que as superações apontadas pela Modernidade não passaram de promessas que estão longe de encontrarem uma realização democrática".

Mais do que em outros tempos históricos, a luta de classes se apresenta nestas primeiras décadas do século XXI como um confronto latente que tem como base as dinâmicas psicológicas de mobilização das massas. Daí o ressurgimento do fascismo em suas novas vestes e simbologias tomando força no cotidiano das massas pela formação da subjetividade, do modo de pensar comum com a modificação de conceitos e mistificação da realidade. Num momento em que ascendem os movimentos políticos mais conservadores e reacionários, o fenômeno psicológico (e ideológico) de manipulação das massas se torna o instrumental de recrudescimento dos preconceitos e mitos, da discriminação e da exclusão dos diferentes com a negação das diferenças, de modo que se acentua a importância de conhecer a gênese da personalidade.

Dessa perspectiva, retomamos o escrito The Authoritarian Personality, publicado originalmente em 1950, em quatro volumes, apresentando os resultados de uma extensa pesquisa sociopsicológica em torno da pergunta: qual a origem desta "espécie 'antropológica' que chamamos o tipo autoritário de homem"? (HORKHEIMER, 1997, p. 7) O tema nos atraiu por ser fundamental nas reflexões que estamos realizando sobre a educação repressiva e as possibilidades de sua superação. Horkheimer se refere diretamente ao processo educativo e 
sua responsabilidade de questionar as relações autoritárias a fim de abrir a senda para novas relações sociais. O Prefácio de Horkheimer, assim como o aporte teórico que fundamenta a pesquisa de Adorno $(1995,1997)$, apesar dos 70 anos de distância histórica, continuam a nos interrogar diante de uma parcela imensa da população mundial que continua a sofrer as mesmas dores e as mesmas humilhações impostas pelo capitalismo desde a sua origem.

Esta "espécie 'antropológica', como acentua Horkheimer (1997, p. 7), parece combinar na sua personalidade "as ideias e a capacidade típicas de uma sociedade altamente industrializada com crenças irracionais e antirracionais". Orgulhoso de seu individualismo, que defende sem se dar conta das bases patrimoniais que precisam sustentá-lo, o homem autoritário vive uma situação contraditória, ao mesmo tempo "ciumento de sua independência e inclinado a submeter-se cegamente ao poder e à autoridade" (HORKHEIMER, 1997, p. 7). O desconhecimento da vivência das contradições dá a medida das tendências ideológicas que fundamentam essa personalidade.

A questão que os autores se colocam está em entender as bases de sustentação do ódio racial e religioso, bem como as possibilidades de sua refutação. Os autores "estão plenamente convencidos de que a ilustração científica sincera e sistemática de um fenômeno de tamanha importância histórica pode contribuir diretamente para a melhoria da atmosfera cultural em que o ódio se desenvolve". E Horkheimer (1997, p. 7) acentua que não se trata de uma posição otimista visto que, na história, já ocorreram "casos de alucinação de massa" que o estudo persistente dos cientistas conseguiu elucidar. O trabalho intelectual "tem tido uma eficácia determinante" no desenvolvimento da sociedade.

Como um dos exemplos, Horkheimer $(1997$, p. 8) recorda a importância das pesquisas e da obra de Freud para a cultura moderna, principalmente pelo fato de "ter tornado o mundo intelectual e principalmente aquele educativo, sempre mais consciente das conexões entre a repressão das crianças (seja no âmbito familiar ou outro) e a ignorância ingênua, da parte da sociedade", da dinâmica psicológica da vida, seja ela infantil ou adulta. A sociedade assimilou e se convenceu ao longo dos anos que os "acontecimentos da primeira infância têm uma importância primária para a felicidade e o potencial de trabalho do adulto", levando a uma mudança nas relações entre pais e filhos. O que o autor acentua aqui, com base em Freud, é que a formação da personalidade se faz no processo de socialização do indivíduo, ou seja, a partir das relações familiares e sociais a criança desenvolve as suas representações emocionais e psicológicas, além das representações racionais, que podem engendrar o seu modo de ser feliz ou reprimido, liberto ou submisso na vida adulta.

O estudo destes autores que, segundo Horkheimer (1997, p. 8), abrem novos caminhos para a pesquisa e para a compreensão dos "fatores sociopsicológicos que consentem ao tipo autoritário de ameaçar de tomar o lugar do tipo individual e democrático que prevaleceu" no contexto da sociedade moderna torna-se de fundamental importância. Aprofundar os estudos sobre as relações autoritárias e a educação repressiva, assim como as condições nas quais elas se desenvolvem, apresenta uma grande importância científica abrindo a "possibilidade de um contra-ataque educativo".

Na sequência apresentamos algumas notas sobre o trabalho citado, especificamente na leitura de Adorno, a fim de retomar nossas reflexões sobre educação repressiva e a necessidade de sua explicitação para, em seguida, colocar algumas características da educação emancipadora a ser construída por meio de um novo projeto de educação. Para as classes populares, a educação formal é de fundamental importância para a sua emancipação política, seu processo formativo a partir do sistema escolar fornece os instrumentos para a leitura da realidade e para a sua autonomia intelectual. Mas existem limitadores sociais desta formação, de modo que precisamos conhecer todo o processo formativo para identificar os limites da educação escolar.

Notas sobre a Personalidade autoritária a partir da leitura de Adorno: "Nunca é lícito a alguém firmar sua paz com a pobreza quando ela cai como uma sombra gigante sobre seu povo e a sua casa" (BENJAMIN, 1987, p. 22).

Sabe-se que o esforço teórico de Adorno nos escritos que elaborou ao longo de sua vida se fez no sentido de explicitar a empiria e efetuar uma renovação de fundo na Teoria Social, o que significou empenhar-se em superar os limites tanto do positivismo quanto do idealismo. Conforme Cohn (2008, p. 21), para Adorno os conceitos, "longe de apenas permitirem reconhecer esse ou aquele fenômeno social", só apresentam consistência se "permitem que a sociedade encontre neles a expressão do que lhe é mais intimamente próprio e não se encontra manifesto naquilo que se observa a olho nu". Os conceitos não devem apenas nomear os fenômenos, mas, sim, permitir "reconhecer o objeto (a sociedade)", mostrando o que lhe é intrínseco, mas se 
encontra escondido. Nesse esforço, Adorno transforma a Sociologia numa "ciência marcada pelo empenho em descobrir na sociedade o que nela é essencial" (COHN, 2008, p. 23).

Retomando as bases da dialética hegeliana, Adorno acentua a negatividade oculta nas relações sociais e que tanto o positivismo quanto o idealismo não conseguem alcançar:

Nessa perspectiva, não é possível pensar a sociedade sem no mesmo passo pensar algo que se distingue dela, mas lhe é inerente, no sentido de que se encontra implicada em seu próprio conceito. Trata-se de seu outro, o indivíduo: o oposto que, longe de confrontá-la externamente, a habita de modo inseparável em convivência tensa (COHN, 2008, p. 32).

O aprofundamento dessas relações e mediações se evidencia em suas aulas, das quais retomamos a de 9 de maio de 1968, a propósito do fascismo. O pressuposto das reflexões é que a "sociedade desenvolve tendências de uma progressiva irracionalidade simultaneamente ao avanço de sua racionalização", o que resulta do permanente antagonismo entre os homens, no qual subjaz o antagonismo de classes, ou seja, a formação dos "diversos processos sociais que, embora amalgamados, provém de interesses divergentes ou contraditórios" (ADORNO, 2008, p. 129). Tais contradições emergem "com particular clareza em situações extremas da sociedade burguesa tardia, como o fascismo" (ADORNO, 2008, p. 130).

Essas observações retornam no texto Educação após Auschwitz, no qual Adorno (1986, p. 33) salienta que "os homens não se compenetraram da monstruosidade cometida", o que abre a "possibilidade da reincidência, no que diz respeito ao estado de consciência e inconsciência dos homens".

Entre as intuições de Freud que realmente alcançam também a cultura e a sociologia parecem-me das mais profundas a que afirma que a civilização produz a anticivilização e a reforça progressivamente. [...] Se no próprio princípio da civilização está implícita a barbárie, então repeti-la tem algo de desesperador (ADORNO, 1986, p. 33) ${ }^{2}$.

Entender a realidade do ponto de vista das contradições que se produzem em seu movimento permite fazer a crítica a todas as formas de exploração e de opressão, que atingem principalmente os socialmente frágeis. Adorno (1986, p. 35) acrescenta que, do ponto de vista sociológico, a "nossa sociedade, embora se integre cada vez mais, incuba simultaneamente tendências desagregadoras". Na medida em que se produzem as condições de esclarecimento e emancipação dos indivíduos, avançam também as condições de restauração conservadora, fruto da estrutura social nascida e consolidada com o capitalismo. Explicitar a dinâmica interna deste processo implica superar uma visão meramente positiva da realidade e reconhecer o conjunto de suas determinações.

Esta questão nos remete diretamente à reflexão sobre a educação, um campo que Adorno acentua ser muito importante, principalmente por sua conotação política, cujo problema é sua apresentação geral muito formal (ADORNO, 2008). É preciso levar em conta as "questões efetivas do poder e da disposição acerca dos meios de produção e da riqueza social situadas por trás dos fenômenos sociais" (ADORNO, 2008, p. 139).

Do ponto de vista da educação, a "democracia, em sua definição formal, ao mesmo tempo em que exige uma educação para a democracia", não exige que se discutam questões espinhosas que possam questionar a situação vigente, de modo que se descuram das questões estruturais que são pressupostas para uma educação política (ADORNO, 2008, p. 140). Pensar em uma educação emancipadora implica, portanto, superar estes limites, sem esquecer que "uma das estratégias mais comuns e eficazes na educação repressiva é criar as condições para que o subalterno, a criança ou o adulto, assimile e interiorize o medo" (SCHLESENER, 2019a, p. 206).

As questões acima expostas são fundamentais para se entender que a formação dos sujeitos tem uma dimensão muito mais ampla do que a escolar e implicam explicitar os mecanismos de formação da subjetividade no contexto da sociedade capitalista, bem como o aflorar dos preconceitos no âmbito da sociedade política. "Uma democracia efetiva só pode ser imaginada enquanto uma sociedade de quem é emancipado" (ADORNO, 1995, p. 142).

Adorno nos fala a partir da realidade social, política e cultural de 1950. O retorno do ideário fascista neste início do século XXI nos leva a retomar suas reflexões para entender como este fenômeno se tornou possível. Tendemos a afirmar que se trata da consolidação de uma ideologia que forma a subjetividade por meio de uma visão de mundo utilitarista e fragmentada que sustenta uma política econômica perversa condizente 
com a nova fase de financeirização do capital. O neoliberalismo apresenta-se como um projeto de sociedade que retoma o que existe de mais retrógrado no pensamento formador do senso comum. Conforme Dardot e Laval (2016, p. 321-322), a concepção neoliberal "vê a sociedade como uma empresa constituída de empresas" e, para consolidar-se, precisa de "uma nova norma subjetiva" para "fazer do homem um animal produtivo e consumidor", ou seja, um novo indivíduo capaz de responder aos interesses econômicos e políticos da classe detentora do poder.

O momento neoliberal caracteriza-se por uma homogeneização do discurso do homem em torno da figura da empresa. Essa nova figura do sujeito opera uma unificação sem precedentes das formas plurais da subjetividade que a democracia liberal permitiu que se conservassem e das quais sabia aproveitar-se para perpetuar sua existência (DARDOT; LAVAL, 2016, p. 326).

Para tanto, torna-se necessário desconstruir a democracia e fragmentar a política, reduzindo-a ao administrativo. Como acentua Boron (2001, p. 179), o "neoliberalismo tem sido um mestre na arte de desacreditar a política e o espaço público". Para destruir a democracia, apresenta-se a política como o "reino dos faladores, vagabundos, irresponsáveis, mentirosos e corruptos". No lugar da política, um moralismo exacerbado alimentado pela religião, um pragmatismo que se diz neutro condenando tudo o que se apresente como crítica ao instituído.

O aspecto educativo desse processo se exprime na lei da eficácia: conforme Dardot e Laval (2016, p. 325), trata-se de adaptar os indivíduos aos interesses do mercado, de "fabricar homens úteis, dóceis ao trabalho, dispostos ao consumo", a consolidação de um projeto que já se delineava no utilitarismo clássico e que com o neoliberalismo toma dimensões internacionais.

Para alcançar estes objetivos a captura da subjetividade do trabalhador (ANTUNES, 2009; DIAS, 2012), o neoliberalismo, na medida em que destrói as bases da democracia, também corrói progressivamente os direitos sociais e lança a classe trabalhadora em uma disputa cruel por condições de sobrevivência.

A corrosão progressiva dos direitos ligados ao status de trabalhador, a insegurança instilada pouco a pouco em todos os assalariados pelas "novas formas de emprego" precárias, provisórias e temporárias, as facilidades cada vez maiores para demitir e a diminuição do poder de compra até o empobrecimento de frações inteiras das classes populares são elementos que produziram um aumento considerável do grau de dependência dos trabalhadores com relação aos empregadores (DARDOT; LAVAL, 2016, p. 329).

O medo de perder o emprego, de passar fome, de não ter onde morar nem como proteger os filhos, paralisa os trabalhadores e os faz aceitar qualquer oferta de trabalho ou desistir de procurar trabalho e tentar sobreviver com alternativas as mais variadas e humilhantes. Mais que a violência física, a violência psicológica vivida cotidianamente por grande parcela da população dificulta qualquer forma de resistência.

Conforme os autores, o medo social expõe todos os assalariados às flutuações do mercado, ao mesmo tempo em que lhes impõe a disputa individual, destruindo as possibilidades de solidariedade coletiva (DARDOT; LAVAL, 2016). O neoliberalismo se apresenta, assim, como uma das políticas econômicas mais agressivas, com uma violência psicológica que desarma as possibilidades de resistência a partir de uma organização coletiva e solidária dos trabalhadores. A articulação da política econômica neoliberal com o recrudescimento do ideário do fascismo destrói as possibilidades de formação de uma consciência histórica e nos mostra um horizonte macabro que vai exigir o esforço e o empenho de gerações para ser revertido, exigindo a crítica e a desconstrução da ideologia neoliberal e repressiva que tomou novas dimensões no senso comum como retomada de preconceitos até então ocultos no inconsciente coletivo. As antigas relações de autoridade familiar e religiosa são reavivadas enquanto modos de ser repressivos que se articulam com o ideário neoliberal e reforçam o conteúdo conservador da educação.

$\mathrm{Na}$ perspectiva das políticas educacionais, os Estados periféricos submetem-se aos preceitos dos organismos internacionais, que subscrevem a política neoliberal, a pretexto de auxiliar as nações periféricas, assessoram os governos na implementação de ideias e instrumentais específicos na formação desta concepção de mundo. Essa posição expressa-se na implementação de currículos que se propõem desenvolver habilidades e competências próprias para exercer funções no mundo do trabalho; em tais políticas transparece a fragmentação do ensino e o fortalecimento do que chamamos de educação repressiva. 
Estes são os pressupostos a partir dos quais entendemos que a questão da personalidade autoritária precisa ser tratada no campo da educação. Se a liberdade e a autonomia individuais na sociedade são inseparáveis do pensamento esclarecedor, a educação repressiva vai na contramão do processo civilizador e um projeto de educação emancipadora precisa questionar suas formulações teóricas e psicológicas.

Dessa perspectiva, o trabalho de Adorno e da equipe envolvida na pesquisa foi explicitar o aspecto irracional das opiniões e comportamentos antissemitas, presentes no modo de pensar e de ser de uma parcela da população estadunidense, a fim de entender a relação entre a constituição da individualidade e seu suporte ideológico, base da psicologia de massas que levou grande parcela da população alemã a aceitar passivamente a ascensão do nazismo. Em outras palavras: como se forma e se consolida o preconceito? Como ele se transmite por meio da educação? Como se produz e se generaliza na formação do indivíduo, mesmo de modo inconsciente, a hostilidade ou o ódio em relação ao diferente? Tais fenômenos não se reduzem a estímulos psicológicos, mas implicam também motivações econômicas resultantes de crises e da própria estrutura do capitalismo, além de transformações na estrutura familiar resultantes de modificações nas relações sociais.

As perguntas que mobilizaram Adorno e os demais pesquisadores foram: Como se apresenta, no pensamento dos indivíduos, a afinidade com o fascismo? Quais as forças internas que mobilizam estes sujeitos? Qual a concepção de ideologia que sustenta este pensamento? As estruturas psíquicas expressam relações sociais e posições políticas interiorizadas a partir da educação repressiva. Como ressalta Crochik na sua leitura do escrito de Adorno, a pesquisa revelou que:

Os que tendiam, conforme as dimensões da Escala $\mathrm{F}$, à agressão e submissão autoritárias, ao pensamento estereotipado, à superstição, ao moralismo sexual, ao cinismo, a ser sadomasoquistas também tendiam a ter altos escores nas escalas acerca do preconceito, e vice-versa; houve também, correlação de menor magnitude, mas ainda assim significante, entre o conservadorismo político econômico e o preconceito. (CROCHIK, 2017, p. 52).

O estudo da estrutura da personalidade revela novas dimensões da ideologia, que se consolidam nas concepções de mundo do senso comum. Adorno, Frenkel-Brunswik e Levinson (1997, p. 20) acentuam que a ideologia se mistifica no discurso: aquilo que o "indivíduo afirma em público quando se sente em segurança em relação as críticas" oculta o que ele verdadeiramente "pensa, mas não diz, o que ele pensa, mas não quer admitir a si mesmo". Estas observações nos lembram o texto de Freud Psicologia das Massas e Análise do $e u$, no qual o autor acentua que o "indivíduo no interior de uma massa experimenta, por influência dela, uma mudança frequentemente profunda de sua atividade anímica", intensificam-se os mecanismos emocionais dos afetos na mesma medida em que diminui a capacidade intelectual de compreender a realidade, levando o indivíduo a nivelar-se ao conjunto das massas (FREUD, 2011, p. 39). A pesquisa dos autores desvela um imaginário fantasioso na figura de um "inimigo imaginário" (ADORNO; FRENKEL-BRUNSWIK; LEVINSON, 1997, p. 171) que desencadeia o ódio irracional. Como acentua Levinson: "uma das formas mais claramente antidemocráticas de ideologia social é o preconceito" que, em qualquer de suas formas (e Levinson salienta o antissemitismo), "representa uma grave ameaça à democracia" (ADORNO; FRENKEL-BRUNSWIK; LEVINSON, 1997, p. 89). O preconceito gera ódio, violência e exclusão social, podendo tornar-se, em termos políticos, uma regressão a formas fantasiosas e míticas de imaginar a realidade.

Sabemos que somos resultado das múltiplas determinações que nos formam no âmbito do social, mesmo que não tenhamos plena consciência disso, visto que existem processos mentais inconscientes que alteram nosso conhecimento racional, lógico, organizado, do mundo. Desvendar este universo oculto buscando os elos existentes entre racional e irracional, entre o imaginário e o real, permite entender melhor fenômenos sociais e identificar traços do passado no presente, a fim de preservar o que ainda existe em termos de democracia.

As reflexões de Adorno, ainda que à distância de setenta anos, são de uma atualidade impressionante ante a realidade de ascensão do neofascismo em âmbito mundial. Mantidas as proporções históricas, as políticas neoliberais aliadas ao ressurgimento de preconceitos que pareciam superados produzem uma situação macabra sempre mais agressiva para com as classes trabalhadoras acentuando a exploração do trabalho e aumentando as desigualdades sociais.

Retomamos Adorno (1986, p. 33), que lembra que "para a educação, a exigência que Auschwitz não se repita é primordial". Surpreende que "tenha merecido tão pouca atenção até hoje". E que se naturalize 
a violência, esquecendo-se a estrutura básica da sociedade e as características repressivas de sua formação (FREUD, 2011).

Acrescentamos uma observação sobre estratégias políticas, nas reflexões de Gramsci (1978) sobre Revolução burguesa italiana e as condições da aliança de Garibaldi com Cavour.

Seu ensinamento é de que, "na luta de classes, em sua dimensão econômica, social e política, precisamos conhecer com clareza e concisão as posições do inimigo" para criar as condições de defesa" (SCHLESENER, 2019a, p. 21). A educação, em sua dimensão política e ideológica, na medida em que forma a personalidade, precisa ser conhecida na sua dimensão repressiva e, na maioria das vezes, oculta, para que possamos construir as bases de uma educação emancipadora.

\section{Educação repressiva x educação emancipadora: por um novo projeto de sociedade}

Auschwitz foi a barbárie, à qual toda a educação se opõe. Fala-se na iminente recaída na barbárie, [...] que subsistirá enquanto as condições que produziram aquela recaída substancialmente perdurarem (ADORNO, 1986, p. 33).

A educação infantil na perspectiva repressiva pode ser entendida como uma forma de adestramento para um determinado comportamento: a criança forma seu caráter a partir da gratificação ou do castigo por um determinado tipo de conduta. Como acentua Galeano (2002, p. 75-76), "para castigo à desobediência e exemplo de liberdade, a tradição familiar perpetua uma cultura do terror que humilha a mulher, ensina os filhos a mentir e contagia tudo com a peste do medo". Ante a violência sofrida ou à violência possível, o medo paralisa e submete à vontade e ao domínio do outro, senhor, pai, patrão.

Freud (2011, p. 46-47) já esclarecia que o processo civilizatório se produz pela repressão e que a disciplina exterior leva à interiorização da autoridade, cuja forma de expressão é o medo e a submissão. A estrutura hierárquica familiar patriarcal, a religiosa ou a militar são estruturas que se mantêm pela coerção externa. Estas estruturas são fundamentais para a manutenção da ordem instituída e se mantêm somente se os subalternos assimilarem o modo de pensar e interiorizarem a disciplina coercitiva.

Embora cada caso tenha a sua particularidade, a "situação de ameaça ou perigo iminente desencadeia mecanismos de autoconservação e de defesa de ordem biológica e psicológica que podem permanecer ao longo da vida" formando a personalidade que, por sua vez, condiciona comportamentos escondendo possíveis desvios (SCHLESENER, 2019a, p. 204). A família tradicional e a religião desempenham uma ação contínua e fundamental para a formação do caráter autoritário e preconceituoso por meio da proibição ou da permissão, da gratificação ou do castigo, formando ideologicamente a subjetividade.

As novas dimensões da ideologia na fase de expansão mundial das comunicações de massa tornamse determinantes na ampliação dos preconceitos e da agressividade própria de quem recebeu uma formação autoritária ao longo de sua vida. Adorno, Frenkel-Brunswik e Levinson (1997, p. 231) entendem que esta situação não pode ser resolvida apenas "no campo educativo, a um nível puramente psicológico, mas requer mudanças decisivas do clima cultural", principalmente com uma efetiva formação política.

Essa formação se torna difícil a partir do momento em que as redes sociais podem desvirtuar os fatos e criar um imaginário social fantasioso, irreal, que pode alimentar o ódio nas suas mais variadas formas. Esse problema se amplia com "a ignorância da complexidade da sociedade contemporânea", alimentada por narrativas fragmentadas e abstratas que podem gerar "um estado de incerteza e de ansiedade geral que constitui o terreno ideal para o tipo moderno de movimento reacionário de massa" (ADORNO; FRENKELBRUNSWIK; LEVINSON, 1997, p. 235). Tem-se, por um lado, ausência de preparação política e, por outro, a divulgação abundante de notícias falsas, formando uma opinião fantasiosa e desconexa, sem a percepção do mundo nas suas contradições e complexidades.

Nas duas primeiras décadas do século XXI o elo entre neoliberalismo e neofascismo se acentuou em âmbito mundial numa nova conjuntura de exploração e expropriação do trabalho, ampliando as formas de extração da mais-valia e concentração do capital. O projeto econômico, político e ideológico neoliberal 
se consolida formando o imaginário social aproveitando-se das novas tecnologias de comunicação como instrumento de consolidação de sua ideologia.

No âmbito da proposta de uma educação emancipadora, torna-se necessário questionar este projeto e elaborar novas estratégias de formação dos sujeitos já a partir da primeira infância. Para tanto, é preciso que nos confrontemos com a repressão e mesmo com o horror diante das atitudes que naturalizam a morte, como se a barbárie não nos atingisse no mais fundo do nosso ser. Adorno (1986, p. 42-43) acentua, a propósito de Auschwitz, "se os homens não fossem profundamente indiferentes ao que acontece com todos os demais [...], então Auschwitz não teria sido possível, pois as pessoas não o teriam aceito". Mas o horror se repete em pleno século XXI: sem falar de genocídios, temos governantes que elogiam reconhecidos torturadores aos quais prestam homenagem. A educação, na sua dimensão política, apresenta-se como um dos caminhos para a emancipação humana neste emaranhado de violências no qual estamos imersos.

A propósito da educação infantil as observações de Buck-Morss (2002, p. 314) sobre o esquecimento da "imagética de um mundo infantil" na obra de Walter Benjamin por parte de seus comentadores pode ser o sintoma de uma educação repressiva e "um problema da maior pertinência política". A educação e a pedagogia burguesas preparam o processo cognitivo da criança adaptando-a desde a infância aos interesses do mundo adulto. Um problema de pertinência política porque se trata do modo como a sociedade se organiza no mundo da produção e das relações sociais e como condiciona o processo de formação da criança definindo o seu futuro.

É política a forma como, na educação burguesa, a cultura é entendida como una e universal e transmitida de forma congelada no tempo e no espaço, como se a história não fosse um movimento de posição e superação de contradições. É político o modo como se ignora a sensibilidade da criança na pressa de formar hábitos e moldar o comportamento. "O verdadeiro aprendizado se realiza na experiência que, enquanto permeada de contradições e conflitos, se concretiza como experiência de enfrentamento e superação de limites" (SCHLESENER, 2019b, p. 160).

Para Adorno (1986, p. 35), não basta interrogar a educação; a questão é social, política e ideológica, sendo necessário conhecer e divulgar os mecanismos (sociopsicológicos) que tornam os homens capazes de genocídios e outras barbáries. O preconceito e a violência se enraízam no sujeito pela educação repressiva: a "educação para a disciplina através da dureza" mostrou-se um grande engano. "Aquele que é duro contra si mesmo adquire o direito de sê-lo contra os demais e se vinga da dor que não teve a liberdade de demonstrar, que precisou reprimir" (ADORNO, 1986, p. 35).

A educação repressiva expressa um projeto de sociedade que, com o recrudescimento do conservadorismo aliado ao discurso e à prática neoliberal, colocam em evidência as fissuras sociais e agravam o estranhamento e a invisibilidade dos pobres, lançados ao sofrimento e ao abandono do Estado.

Para as classes subalternas resistir e ter no horizonte um outro projeto de sociedade, que é o pressuposto para uma educação emancipadora a ser construída em bases materialistas e dialéticas, implica uma atualização do passado na sua dimensão política, a fim de romper com o horizonte ideológico positivista e pragmático que forma o senso comum. Conhecer a história em suas múltiplas determinações permite explicitar o processo de transmissão cultural no qual "todos os que até hoje venceram participam do cortejo triunfal, em que os dominadores de hoje espezinham os corpos dos que estão prostrados no chão" (BENJAMIN, 1985, p. 225). Esta releitura da história é vital para se elaborar e propor uma nova pedagogia.

A educação, tanto em seu sentido abrangente quanto no contexto escolar, é a medida da liberdade e, como tal, é eminentemente política. Porém, no âmbito da sociedade moderna a formação da personalidade e de um pensamento autônomo se confronta com a barreira da estrutura social, fundada na divisão social do trabalho e na reprodução do sistema. As condições de uma educação emancipadora se encontram no questionamento e na superação dessa estrutura. Questionar-se sobre o processo educativo implica uma compreensão da totalidade social a fim de refletir e questionar o processo civilizatório na formação do ser humano preconceituoso, racista, violento, identificando as formas e a extensão da retificação.

A ascensão de movimentos conservadores e reacionários em âmbito mundial, articuladas ao ideário neoliberal, a violência e a barbárie instituídas e naturalizadas, nos mostram a atualidade das reflexões de Adorno, Frenkel-Brunswik e Levinson (1997) e os demais pesquisadores sobre a personalidade autoritária. Retomar essas reflexões nos permitem criar formas de resistência ao império do irracional e abrir novas sendas de construção de uma educação emancipadora. 


\section{Considerações Finais}

“Temos de emancipar a nós mesmos antes de poder emancipar outros" (MARX, 2010, p. 34). É importante acentuar que não deveríamos ter que argumentar em defesa de uma educação emancipadora, porque toda educação deveria ser assim. E todo discurso que enuncia a emancipação, mas não põe em discussão o modo de produção capitalista e a ordem instituída apresenta-se como um discurso abstrato, parcial e, portanto, inócuo. É o caso de alguns conceitos recorrentes na área da educação, como gestão democrática, por exemplo, que exige explicitar de qual gestão e de qual democracia se está falando; sem explicitar o contexto e o movimento da história em suas contradições ficamos no horizonte ideológico do pensamento dominante, sem atingir a realidade efetiva.

Consideramos três pontos fundamentais:

a) A educação realiza-se na vida enquanto um processo de conhecimento de si no mundo a partir das condições sociais e políticas nas quais estamos inseridos e a escola é apenas uma das instituições formadoras na sociedade. Na sociedade capitalista a escola cumpre as exigências materiais e simbólicas necessárias para a manutenção da ordem econômica instituída, preparando para a inserção no mundo do trabalho.

b) A escola tem a função primordial de formação para o trabalho, mas pode ainda possibilitar as condições de emancipação política pela formação de um pensamento autônomo. Nesse caso, cumpre os objetivos do ideário liberal, preservando a identidade e a pluralidade dos sujeitos capazes de reconhecer suas raízes sociais e culturais e qualificando a sua participação na sociedade. Uma emancipação radical das classes populares exigiria que estas tomassem o controle da escola e do seu processo educativo.

c) Com base em nossas circunstâncias históricas, uma educação emancipadora precisaria partir do reconhecimento das contradições que permeiam a vida social para poder confrontar o neoliberalismo com um novo projeto de sociedade. Pressuporia uma mudança estrutural das condições da escola e das condições de formação continuada dos professores, a fim de viabilizar uma emancipação efetiva dos sujeitos.

A partir do entendimento de que a história é movimento e que toda educação é política, precisamos entender que, ao falarmos em educação emancipadora, temos que pressupor a educação repressiva como constituinte da estrutura da sociedade e que é de fundamental importância explicitar este pressuposto, a fim de criar condições de formação e as possibilidades de uma educação emancipadora.

\section{Referências}

ADORNO R. N. S. T.; FRENKEL-BRUNSWIK E.; LEVINSON D. J. La personalita autoritaria. La misurazione dele tendenze ideologiche. [S. 1.]: Edizioni di Comunita, 1997.

ADORNO, T. W. Educação após Auschwitz. In: ADORNO, T. W. Sociologia. São Paulo: Ática, 1986. p. 33-45.

ADORNO, T. W. Educação e emancipação. Rio de Janeiro: Paz e Terra, 1995.

ADORNO, T. W. Introdução à Sociologia. São Paulo: Editora UNESP, 2008.

ANTUNES, R. Da pragmática da especialização fragmentada à pragmática da liofilização flexibilizada: as formas da educação no modo de produção capitalista. Germinal, Marxismo e educação em debate, Salvador, v. 1, n. 1, p. 25-33, jun. 2009.

BENJAMIN, W. Obras Escolhidas I: magia e técnica, arte e política. São Paulo: Brasiliense, 1985.

BENJAMIN, W. Obras Escolhidas II: Rua de Mão Única. São Paulo: Brasiliense, 1987.

BORON, A. A Coruja de Minerva: mercado contra democracia no capitalismo contemporâneo. Petrópolis: Vozes, 2001

BUCK-MORSS, S. Dialética do Olhar: Walter Benjamin e o Projeto das Passagens. Belo Horizonte: UFMG, 2002.

COHN, G. Apresentação à Edição Brasileira: a Sociologia como Ciência Impura. In: ADORNO, T. W. Introdução à Sociologia. São Paulo: Editora UNESP, 2008. p. 19-34.

CROCHIK, J. L. Personalidade Autoritária e pesquisa empírica com a escala F: alguns estudos brasileiros. Revista Impulso, Piracicaba, v. 27, n. 69, p. 49-64, 2017. Disponível em: https://www.metodista.br/revistas/revistas-unimep/index.php/impulso/article/view/3325. Acesso em: 18 ago. 2020.

DARDOT, Pierre e LAVAL, Christian. A nova razão do mundo: ensaio sobre a sociedade neoliberal. São Paulo: Boitempo, 2016. 
DIAS, E. F. Revolução passiva e modo de vida: ensaio sobre as classes subalternas, o capitalismo e a hegemonia. São Paulo: Sundermann, 2012.

FREUD, S. Psicologia das massas e análise do eu e outros textos (1020-1923). São Paulo: Companhia das Letras, 2011.

GALEANO, Eduardo. O Livro dos Abraços. Porto Alegre: L \& PM, 2002.

GONÇALVES, M. A. Prefácio. In: LEINER, P. C. O Brasil no espectro de uma guerra híbrida: militares, operações psicológicas e políticas em uma perspectiva etnográfica. São Paulo: Alameda, 2020.

GRAMSCI, A. Quaderni del Carcere. Torino: Einaudi, 1978.

HORKHEIMER, M. Prefácio. In: ADORNO R. N. S. T.; FRENKEL-BRUNSWIK E.; LEVINSON, D. J. La personalita autoritária: la misurazione dele tendenze ideologiche. [S. 1.]: Edizioni di Comunita, 1997.

JERVIS, Giovanni. Introduzione. In: ADORNO, Theodor W. et al. (Orgs.) La personalità autoritaria. Milano: Mondadori, 1997 , v. 1. MARX, K. Sobre a questão judaica. São Paulo: Boitempo, 2010.

SCHLESENER, A. H. Educação repressiva: as várias formas de repressão na formação da sociedade. Ponta Grossa: Editora UEPG, 2019a. SCHLESENER, A. H. Mosaicos, colagens, desvios, passagens: a educação a partir de Walter Benjamin. Curitiba: Editora UTP, $2019 \mathrm{~b}$. STEFANUTO, J. R. R.; BUENO, S. F. A recusa dos direitos humanos como manifestação de ressentimento e autoritarismo. RIDH, Bauru, v. 8, n. 1, p. 33-44, 2020.

\section{Notas}

1 Conforme Gonçalves (2020, p. 8-9), o Estado brasileiro foi tomado por forças que se utilizaram das redes sociais para formar um consenso de ódio contra o PT; o autor acentua que se criou um "cenário de guerra híbrida cuja fórmula consiste em sistematicamente inverter os enunciados" de modo a formar uma concepção imaginária do social e do político. A estratégia de retorno ao poder pelos militares tem a "'guerra híbrida' como categoria fundante de uma nova significação do voto e do eleitor que passam a fazer parte das maquinações guerreiras, das armadilhas psicológicas, das contendas morais" que dão uma "nova significação e configuração de democracia na atualidade".

2 O que aconteceu com os judeus na Segunda Guerra Mundial continua a acontecer em regiões da África, no Curdistão e, não podemos esquecer, na Palestina.

\section{Anita Helena Schlesener}

anitahelena1917@gmail.com

Doutorado em História pela Univeridade Federal do Paraná (UFPR)

Docente da Universidade Tuiuti do Paraná (UTP)

Coordenadora do Programa de Pós-graduação em Educação Universidade Tuiuti do Paraná (UTP)

\section{UTP}

Rua Sydnei Antonio Rangel Santos, 238

Santo Inácio Curitiba - PR

Curitiba - PR - Brasil

CEP: $82010-330$

\section{Agradecimentos}

Ao CNPq, pela possibilidade de desenvolver esta pesquisa. Agência financiadora

Bolsa Produtividade em Pesquisa - CNPq. Processo 301973/2019-9.

Contribuições das autoras

Não se aplica.

\author{
Aprovação por Comitê de Ética \\ Não se aplica. \\ Consentimento para publicação \\ Consentimento as autora. \\ Conflito de interesses
}

Não há conflito de interesses. 